\title{
An Intuitionistic Fuzzy Simple Additive Weighting (IFSAW) Method for Selection of Vendor
}

\author{
Prabjot Kaur ${ }^{*}$, Sanjay Kumar \\ Department of Applied Mathematics , \\ Birla Institute of Technology, Mesra, \\ Ranchi-835215,Jharkhand,India
}

\begin{abstract}
Selecting the right vendor from a large number of possible vendors is a non-trivial task, in which multiple criteria need to be examined carefully. The Multiple criteria decision making provides an effective framework for vendor comparison based on the evaluation of multiple conflict criteria. The decision maker's information on the conflicting criteria is imprecise due to lack of time or lack of data. Intuitionistic fuzzy set (IFS) is a very suitable tool to describe the imprecise decision information and deal with the uncertainty and vagueness in decision making. In this study, we propose an approach based on intuitionistic fuzzy SAW method to select an appropriate vendor. We use the simple operation of intuitionistic fuzzy arithmetic operation for calculating the aggregation score for each vendor. Finally a score function is used to rank the vendors with largest score. A numerical example illustrates our proposed approach.
\end{abstract}

\section{Introduction}

A number of fuzzy multi-criteria decision making approaches have been proposed for supplier selection. These approaches enable us to deal with evaluation; selecting and ranking vendors in a fuzzy environment.Chen et al. (2006) presented a fuzzy hierarchical model to deal with the supplier selection problem. Sarkar and Mohapatra (2006) used the fuzzy set approach to account for the imprecision involved in numerous subjective characteristics of suppliers. Kahraman et al. (2003) applied a fuzzy AHP to select the best supplier in a Turkish white good manufacturing company. Chan and Kumar (2007) also used fuzzy synthetic extent analysis AHP method for supplier selection. Bottani and Rizzi (2008) developed an integrated cluster analysis, AHP and fuzzy logic to group and rank alternatives, and to progressively reduce the amount of alternatives and select the most suitable cluster. Jain et al. (2004) suggested an integrated GA and fuzzy based approach for supplier selection.Amid et al. (2006) developed a fuzzy multi-objective linear programming model for supplier selection. Bevilacqua et al. (2006) applied quality function deployment (QFD) approach for supplier selection. Kwong et al. (2002) and Chou and Chang (2008) applied fuzzy set theory in SMART to evaluate the suppliers in their various case studies.

One thing the fuzzy sets lack is non-membership function. The information expressed by fuzzy sets is not complete in context of decision making because alternatives satisfy the attributes but no arrangements for alternatives dissatisfying the attributes. Atanassov(1986) characterized the IFS by expressing it in terms of membership function and non-membership function, such that the sum of both values is less than one.Thus intutionistic fuzzy set theory seems to be very useful for modelling situations with missing information or hesitance.

Intuitionistic fuzzy sets has found popularity and is being studied and applied in various fields of science.IF set theory has been successfully applied to solve various decision making problems $\mathbf{L i} \boldsymbol{\&}$ Wang(2008), Li(2005,2008), Szmidt \& Kacprzyk(1996a,1996b,1997,2002), medical diagnostic reasoning Eulalla Szmidt and Janusz Kacprzyk(2004),Athar Kmaral(2009), assignment problems Sathi Mukherjee and Kajla Basu(2011), facility location selection Fatih Emre Boran (2011), QoS-aware web services selection Ping Wang(2009), supplier selection Zixue Guo,Meiran Qi and Xin Zhao(2010).

We will present here an intuitionistic fuzzy set as a tool in MADM method of SAW for a more human consistent reasoning under imperfectly defined facts and imprecise knowledge. The gist of the paper is as follows: section two introduces the basic definitions of intutionistic fuzzy sets. Section three explains the intutionistic fuzzy SAW algorithm to be used in the paper. Section four gives an illustration of selecting a material supplier using the proposed algorithm. Section five gives the conclusion we reach while using this approach.

\section{Intuitionistic Fuzzy Sets [Atanassov(1986)]}

Definition 1.1: An intuitionistic fuzzy set (IFS, for short) A on a universe $U$ is defined as an object of the following form: $\mathrm{A}=\left\{\left(\mathrm{u}, \mu_{\mathrm{A}}(\mathrm{u}), \mathrm{v}_{\mathrm{A}}(\mathrm{u})\right) / \mathrm{u} \varepsilon \mathrm{U}\right\}$ where the functions $\mu_{\mathrm{A}}: \mathrm{U} \rightarrow[0,1]$ and $\mathrm{v}_{\mathrm{A}}: \mathrm{U} \rightarrow[0,1]$ define the degree 
of membership and the degree of non membership of the elements $u \varepsilon U$ in A, respectively, and for every $u \varepsilon U$ : $0 \leq \mu_{\mathrm{A}}(\mathrm{u})+\mathrm{v}_{\mathrm{A}}(\mathrm{u}) \leq 1$.

Definition 1.2: The value of $\pi_{A}(u)=1-\mu_{A}(u)-v_{A}(u)$ represents the degree of hesitation(or uncertainty) associated with the membership of elements u\&U in IFS A. We call it intutionistic fuzzy index of A with respect of element $u$.

Definition 1.3: Let A and B are IFS s of the set X, then multiplication operator is defined as follows: $\mathrm{A} \odot \mathrm{B}=\left\{\mu_{A}(x), \mu_{B}(x), v_{A}(x)+v_{B}(x)-v_{A}(x) \cdot v_{B}(x), 1-\left(\left(\mu_{A}(x) \cdot \mu_{B}(x)\right)-\left(v_{A}(x)+v_{B}(x)-v_{A}(x) \cdot v_{B}(x)\right)\right\} \ldots(1)\right.$

Definition 1.4: Let $\tilde{a}=(\mu, \mathrm{v})$ be an intuitionistic fuzzy number, a score function $\mathrm{S}$ of an intuitionistic fuzzy value can be represented as follows [39]:

$$
\mathrm{S}(\tilde{a})=\mu-\mathrm{v}, \mathrm{S}(\tilde{a}) \varepsilon[-1,1]
$$

If $\mathrm{S}$ is the largest value among the values $\{\mathbf{S}(\widetilde{\boldsymbol{a}})\}$, then the alternative $\mathrm{A}_{\mathrm{i}}$ is the best choice.

\section{Intuitionistic Fuzzy Saw Algorithm}

The SAW method known as a simple additive weight method, is the best known and widely used MADM method developed by Hwang \& Yoon(1981). The basic principle of SAW is to obtain a weighted sum of the performance ratings of each alternative under all attributes.

Suppose we have $A_{1}, A_{2}, A_{3} \ldots \ldots A_{n}$ be $n$ alternatives called vendors. Let $C_{1}, C_{2}, C_{3} \ldots, C_{m}$,be the criteria to evaluate vendors. Furthermore we assume that the weight of criteria supplied by decision makers are represented by a weighting vector $\mathrm{W}=\left\{\mathrm{W}_{1}, \mathrm{~W}_{2}, \mathrm{~W}_{3} \ldots, \mathrm{W}_{\mathrm{n}}\right\}$, where $\mathrm{W}_{1}, \mathrm{~W}_{2}, \mathrm{~W}_{3} \ldots, \mathrm{W}_{\mathrm{n}}$ are represented by intuitionistic fuzzy sets defined as follows:

$$
\mathrm{W}_{\mathrm{j}}=\left\{\mu_{\mathrm{w}}\left(\mathrm{x}_{\mathrm{j}}\right), \mathrm{V}_{\mathrm{w}}\left(\mathrm{x}_{\mathrm{j}}\right), \pi_{\mathrm{w}} \mathrm{x}(\mathrm{j})\right\} \text {, where } \mathrm{j}=1,2, \ldots, \mathrm{n} \text {. }
$$

The computational procedure for Intuitionistic fuzzy SAW is being presented as follows:

Step 1: Construct an intuitionistic fuzzy decision matrix: $\widetilde{\boldsymbol{R}}=\left(\widetilde{\boldsymbol{r}_{i j}}\right)_{\mathrm{mxn}}$ is an intuitionistic fuzzy decision matrix such that:

$$
\tilde{R}=\left(\begin{array}{ccc}
\widetilde{\boldsymbol{r}_{11}} & \cdots & \tilde{\boldsymbol{r}}_{1 n} \\
\vdots & \ddots & \vdots \\
\tilde{\boldsymbol{r}}_{m 1} & \cdots & \tilde{\boldsymbol{r}}_{m n}
\end{array}\right)
$$

Where $\widetilde{\mathbf{r}_{i j}}=\left(\boldsymbol{\mu}_{\mathrm{ij}}, \mathbf{v}_{\mathbf{i j}}, \boldsymbol{\pi}_{\mathbf{i j}}\right)(\mathrm{i}=1,2, \ldots, \mathrm{m} ; \mathrm{j}=1,2, \ldots, \mathrm{n})$, which are contained in intuitionistic fuzzy decision matrix. In $\widetilde{\mathbf{r}_{\mathrm{ij}}}$ , $\mu_{\mathrm{ij}}$ indicates the degree that the alternative $A_{i}$ satisfies the attribute $C_{j}$ and $v_{i j}$ indicates the degree that the alternative $\mathrm{A}_{\mathrm{i}}$ does not satisfy the attribute $\mathrm{Cj}$.

STEP 2: Performing the transformation operation by using equation (1) we obtain the total intuitionistic fuzzy scores $\mathrm{V}\left(\mathrm{A}_{\mathrm{i}}\right)$ for individual vendors by multiplying the intuitionistic fuzzy weight vectors $(\mathrm{W})$ by intuitionistic fuzzy rating matrix $(\mathrm{R})$.

$$
\mathrm{V}\left(\mathrm{A}_{\mathrm{i}}\right)=\mathrm{R} \odot \mathrm{W}=\sum_{i=1}^{m}\left[\left\{\mu_{\mathrm{Ai}}\left(\mathrm{x}_{\mathrm{j}}\right), \mathrm{v}_{\mathrm{Ai}}\left(\mathrm{x}_{\mathrm{j}}\right), \pi_{\mathrm{Ai}}\left(\mathrm{x}_{\mathrm{j}}\right)\right\} *\left\{\mu_{\mathrm{w}}\left(\mathrm{x}_{\mathrm{j}}\right), \mathrm{v}_{\mathrm{w}}\left(\mathrm{x}_{\mathrm{j}}\right), \pi_{\mathrm{w}}\left(\mathrm{x}_{\mathrm{j}}\right)\right] \ldots(3)\right.
$$

STEP 3: Rank the alternatives.Applying equation (2) to obtain a crisp score function $S\left(A_{1}\right), S\left(A_{2}\right), \ldots, S\left(A_{n}\right)$ for the various alternatives. The largest value of $S\left(A_{j}\right)$ among $S\left(A_{1}\right), S\left(A_{2}\right), \ldots, S\left(A_{n}\right)$ represents the best alternative or vendor.

Step 4: We compare our approach with Jun Ye(2010) on weighted correlation coefficient under intuitionistic fuzzy environment.

\section{Numerical Example}

In this section, the example shown in Zixue Guo,Meiran Qi and Xin Zhao (2010) is used to illustrate the selection of supplier is employed in the proposed system.

Step 0: An enterprise wants to select a suitable material supplier [*]. After preliminary screening, four alternatives $A_{1}, A_{2}, A_{3}$ and $A_{4}$ remain for evaluation and selection. Five criteria are considered:

1. Product Quality $\left(\mathrm{C}_{1}\right)$

2. Price $\left(\mathrm{C}_{2}\right)$

3. Technical capability $\left(\mathrm{C}_{3}\right)$

4. Delivery $\left(\mathrm{C}_{4}\right)$

5. Service $\left(\mathrm{C}_{5}\right)$

6. Flexibility $\left(\mathrm{C}_{6}\right)$

The proposed method is applied to solve this problem and computational procedure is summarized as follows:

\begin{tabular}{|c|c|c|c|c|c|c|}
\hline & $\mathrm{C}_{1}$ & $\mathrm{C}_{2}$ & $\mathrm{C}_{3}$ & $\mathrm{C}_{4}$ & $\mathrm{C}_{5}$ & $\mathrm{C}_{6}$ \\
\hline $\mathrm{A}_{1}$ & $(.6,3,1,1)$ & $(.5, .3,2)$ & $(.4,3,3)$ & $(.5, .4, .1)$ & $(.9,0, .1)$ & $(.2, .5, .3)$ \\
\hline $\mathrm{A}_{2}$ & $(.6,3,1)$ & $(.7,1,1,2)$ & $(.4, .1, .5)$ & $(.5, .3, .2)$ & $(.7,2,2,1)$ & $(.2, .4, .4)$ \\
\hline $\mathrm{A}_{3}$ & $(.4, .2,4)$ & $(.4,3,3)$ & $(.4,3,3)$ & $(.6,2,2)$ & $(.8,1,1,1)$ & $(.2, .5, .3)$ \\
\hline $\mathrm{A}_{4}$ & $(.6,3,1)$ & $(.3, .1,6)$ & $(.1, .4,5)$ & $(.7, .2, .1)$ & $(.5,2,2,3)$ & $(.3,3, .4)$ \\
\hline
\end{tabular}
Step 1:.Construct the intuitionistic fuzzy decision matrix. The intuitionistic fuzzy decision matrix has been constructed in Table 1.

Table 1: The intuitionistic fuzzy decision matrix 
The weights for the criteria are given in Table 2.

Table 2: Weights of the criteria

\begin{tabular}{|l|l|l|l|l|l|l|}
\hline $\mathrm{w}_{\mathrm{j}}$ & $\mathrm{C}_{1}$ & $\mathrm{C}_{2}$ & $\mathrm{C}_{3}$ & $\mathrm{C}_{4}$ & $\mathrm{C}_{5}$ & $\mathrm{C}_{6}$ \\
\hline & $(.2, .4,4)$ & $(.2, .2, .6)$ & $(.1, .5, .4)$ & $(.15, .5, .35)$ & $(.25, .3,4)$ & $(.1,3, .6)$ \\
\hline
\end{tabular}

Step 2:

The total intuitionistic fuzzy score $\mathrm{V}\left(\mathrm{A}_{\mathrm{i}}\right)$ for each vendor is calculated is using equation (3) and is as follows:

$\mathrm{V}\left(\mathrm{A}_{1}\right)=[(.2, .4,4) *(.6, .3, .1)]+[(.5, .3, .2) *(.2, .2, .6)]+[(.4, .3, .3) *(.1, .5, .4)]+[(.5, .4, .1) *(.15, .5, .35)]$

$+[(.9,0, .1) *(.25, .3, .4)]+[(.1, .3, .4) *(.2, .5, .3]$

$\mathrm{V}\left(\mathrm{A}_{1}\right)=\left[.2^{*} .6 ; .4+.3-.4^{*} .3 ; 1-\left(.2^{*} .6+.4+.3-.4^{*} .3\right)\right]+\left[.5^{*} .2 ; .3+.2-.3^{*} .2 ; 1-\left(.5^{*} .2+.3+.2-.3 * .2\right)\right]$

$+\left[.4^{*} .1 ; .3+.5-.3 * .5 ; 1-(.4 * .1+.3+.5-.3 * .5)\right]+[.5 * .15 ; .4+.5-.4 * .5 ; 1-(.5 * .15+.4+.5 .4 * .5)]$

$+[.9 * .25 ; .3+.0-.3 * .0 ; 1-(.9 * .25+.3+.0-.3 * .0)]+[.1 * .2 ; .3+.5-.3 * .5 ; 1-(.1 * .2+.3+.5-.3 * .5)]$

$=[(.12, .58, .30)+(.1, .44, .3)+(.04, .65, .31)+(.075, .70, .225)+(.225, .3, .475)+(.02, .65, .33)]$

$=[.5799 ; .022 ; .3981]$

Similarly we calculate the intuitionistic fuzzy scores for the other vendors.

$\mathrm{V}\left(\mathrm{A}_{2}\right)=[.5699,, 01, .4201]$

$\mathrm{V}\left(\mathrm{A}_{3}\right)=[.5099, .01, .4801]$

$V\left(A_{4}\right)=[.4499, .012, .5381]$

Step 3:

The score function for each vendor is calculated using equation (2) and is as follows:

$\mathbf{S}\left(\mathbf{A}_{\mathbf{1}}\right)=.5799-.022=.5579$

$\mathbf{S}\left(\mathbf{A}_{2}\right)=.5599$

$\mathbf{S}\left(\mathbf{A}_{\mathbf{3}}\right)=.4999$

$\mathrm{S}\left(\mathbf{A}_{4}\right)=.4387$

Step 4:

The vendor with the largest score function value is $A_{2}$.the ranking order is as follows:

Step 5:

$$
\mathbf{A}_{2}>\mathbf{A}_{1}>\mathbf{A}_{3}>\mathbf{A}_{4}
$$

The ranking order for vendor $A_{2}$ is in agreement with Jun Ye (2010) result on weighted correlation coefficient under intuitionistic fuzzy environment.

i.e. $\mathbf{A}_{2}>\mathbf{A}_{1}>\mathbf{A}_{4}>\mathbf{A}_{3}$.

\section{Conclusions}

In this paper we have presented a new application of an intuitionistic fuzzy set approach using the intuitionistic fuzzy arithmetic operations in SAW method. We have presented a numerical example to illustrate our method for vendor selection problem in an intuitionistic environment. From the illustrated example we see that the proposed method of IFS can efficiently handle the vendor selection problem when available information is not sufficient to handle imprecise concepts.

\section{References}

[1]. Amid, A., Ghodsypour, S.H., O’Brien, C., 2006. Fuzzy multiobjective linear model for supplier selection in a supply chain. International Journal of Production Economics 104 (2), 394-407.

[2]. Atanassov K. (1986) Intuitionistic fuzzy sets, Fuzzy Sets and Systems, 20 (1986) 87-96.

[3]. Athar Kmaral,Homopathic drug selection using intutionistic fuzzy sets,Homeopathy (2009),98,35-39.

[4]. Bevilacqua, M., Ciarapica, F.E., Giacchetta, G., 2006. A fuzzy-QFD approach to supplier selection. Journal of Purchasing and Supply Management 12 (1),14-27.

[5]. Bottani, E., Rizzi, A., 2008. An adapted multi-criteria approach to suppliers and products selection - An application oriented to lead-time reduction. International Journal Production Economics 111 (2), 763-781.

[6]. Chan, F.T.S., Kumar, N., 2007. Global supplier development considering risk factors using fuzzy extended AHP-based approach. OMEGA - International Journal of Management Science 35 (4), 417-431.

[7]. Chen, C.T., Lin, C.T., Huang, S.F., 2006. A fuzzy approach for supplier evaluation and selection in supply chain management. International Journal of Production Economics 102 (2), 289-301.

[8]. Chou, S.Y., Chang, Y.H., 2008. A decision support system for supplier selection based on a strategy-aligned fuzzy SMART approach. Expert Systems with Applications ,34 (4), 2241-2253.

[9]. Hwang, C.L. and Yoon, K. Multiple Attributes Decision Making Methods and Applications, Springer, Berlin, Heidelberg, 1981.

[10]. Jain, V., Tiwari, M.K., Chan, F.T.S., 2004. Evaluation of the supplier performance using an evolutionary fuzzy-based approach. Journal of Manufacturing Technology Management 15 (8), 735-744.

[11]. Kahraman, C., Cebeci, U., Ulukan, Z., 2003. Multi-criteria supplier selection using fuzzy AHP. Logistics Information Management 16 (6), 382-394. 
[12]. D. F. Li, Multiattribute decision making models and methods using intuitionistic fuzzy sets., Journal of Computer and System Science, 70(2005), 73-85.

[13]. H.W. Liu and G.J. Wang, Multi-criteria decision-making methods based on intuitionistic fuzzy sets, European Journal of Operational Research, 179(2007), 220-233.

[14]. E. Szmidt and J. Kacprzyk, Group decision making via intuitionistic fuzzy sets.FUBEST'96,October 9-11, Sofia, Bulgaria, (1996a), 107-112.

[15]. E. Szmidt and J. Kacprzyk, Intuitionistic fuzzy sets for more realistic group decision making.International Conference on Transition to Advanced Market Institutions and Economies, Warsaw,June 18-21, (1997), 430-433.

[16]. E. Szmidt and J. Kacprzyk, Using intuitionistic fuzzy sets in group decision making, Control and Cybernetics, 31(2002), 10371053.

[17]. E. Szmidt and J. Kacprzyk, Intuitionistic fuzzy sets in group decision making., NIFS, 2 (1) (1996b), 15-32.

[18]. Eulalla Szmidt and Janusz Kacprzyk,Medical diagnostic reasoning using a similarity measure for intutionistic fuzzy sets,Eighth Int. Conference. On IFSs, Varna,20-21,June 2004,NIFS vol.10(2004),4,61-69.

[19]. Sathi Mukherjee and Kajla Basu, Solving intutionistic fuzzy assignment problem by using similarity measures and score functions,Int. J. Pure, Science Technology,2(1),2011,pp.118.

[20]. Deng Feng Li, Extension of the LINMAP for multiattribute decision making under Atanassov's intutionistic fuzzy environment, Fuzzy optimization decision making (2008),7:17-34,

[21]. Jun Ye, Fuzzy decision making method based on the weighted correlation coefficient under intuitionistic fuzzy environment, European Journal of Operational Research ,205(2010),202-204.

[22]. Zixue Guo,Meiran Qi and Xin Zhao,A new approach based on intuitionistic fuzzy set for selection of suppliers,2010,IEEE 2010 sixth international conference on Natural Computation (ICNC 2010).

[23]. Ping Wang, QoS-aware web services selection with intuitionistic fuzzy set under consumer's vague perception, Expert Systems with Applications 36(2009),4460-4466.

[24]. Fatih Emre Boran,An integrated intuitionistic fuzzy multicriteria decision making method for facility location selection,Mathematical and Computational Applications ,vol 16(2),487-496,2011. 